\title{
Research on the Artistic Language of Fiber Murals
}

\author{
Xing Wenwen ${ }^{1}$ \\ ${ }^{1}$ Shandong University of Arts, Jinan, Shandong, 250014, China
}

Keywords: fiber fresco; art language; relationship

\begin{abstract}
Through the historical review and analysis of the development of fiber murals, this paper explores the features and classification of fiber mural languages from the aspects of material, craftsmanship and space of mural materials, and ultimately enriches and improves the artistic language of contemporary murals.
\end{abstract}

\section{Introduction}

The term "fiber" is used in the Encyclopedia Britannica to explain that in the production of textiles, the unit body of yarns and fabrics is of appropriate length, flexibility and strength. Fiber is one of the materials most closely related to human life. Starting from our ancestors' "knot of ropes," the "fiber" material has entered the real world through people's dexterous hands. The art of fiber originated in the West. It is a literal translation of the English "Fiber Art". The term "Fiber Art" was a term coined in the 1970s. The fiber art is based on fiber materials as the main medium for creation. It is based on a variety of animal and plant fibers (including hemp, cotton, wool, grass, rattan, silk, etc.) and man-made fibers synthesized using artificial techniques (including chemical fiber, Nylon, metal, etc.) or directly using off-the-shelf manufactured products as materials, using knitting, weaving, knotting, binding, winding, wrapping, pasting, arranging, and other means of production to create a flat or three-dimensional image of an art form [1].

\section{The Origin and Development of Fiber Murals}

The history of Chinese fiber weaving has a long history. Since mankind knows to protect the body and resist the cold, humans have knitted objects. Gepian fragments unearthed in Caoxieshan, Wu County, Jiangsu Province are the earliest fiber products found in China. This shows that in the Neolithic Age humans used woven natural materials such as hemp and bamboo to weave various fiber products. Until the Xia, Shang, and Zhou dynasties, sericulture in China had become more developed, and embroidery and handicrafts gradually appeared. During the Warring States period, organizations that began to manage the production of silk fabrics were able to not only weave fine plain weaves but also weave complex twills. We were also able to jacquard and embroider, and as many as a dozen patterns were varied. From the Qin and Han Dynasties to the Sui and Tang dynasties, embroidery and tapestry reached a very high artistic level. In the Ming and Qing Dynasties, China had a long history of weaving and embroidery. The scale of silk weaving workshops has grown and it has gradually grown to the people. It is also famous for its embroidery. The four famous embroideries are Suzhou embroidery, Yuexiu embroidery, Qiang embroidery and Xiang embroidery. After the founding of New China, China's carpet industry has made even greater progress. Especially in the 1970s, carpets, as a major variety of Chinese traditional arts and crafts, have been greatly developed [2].

In the West, the history of fiber weaving can be traced back to the ancient Egypt in the 15th century BC. The linen tapestry excavated in the area is the earliest wall hanging fabric found in the world so far. Its weaving technology is very similar to the modern process. During the Renaissance, religious theology gradually withdrew from the leadership position, and in all fields of the West, due to the development of the natural sciences, it led to change. From the point of view of art appreciation, people generally pursue the concept of pursuing art to reflect real life. This aesthetic psychology urges artists to use tapestries as a means of expression to reflect frequently expressed 
content in paintings, so as to achieve relatively novel visual effects. Therefore, faithfully mimicking the effect of painting becomes the main theme of the art of tapestry [3].

In the 17th and 18th centuries, Baroque and Rococo, the tapestry pursued glitz and the high-gypsum tapestry reached its peak period. The materials used in the tapestry began to be enriched. Gold and silver lines and new weaving techniques were applied to the tapestry. Fascinating artwork, but also a symbol of status. It is worth mentioning that France has also set up a Kopilin Weaving Institute dedicated to court services. At this time, the tapestry has truly integrated practicality and decorativeness, and it has rapidly spread in Europe. At this time, the color of European tapestries was much more abundant than in the Middle Ages [3].

In the second half of the 19th century, the artistic thinking of the art and craft movement promoted the development of fiber art. Artists represented by William Morris focus on the traditional forms of fiber arts, claiming that breakthroughs at the time of wall hangings were merely imitating the limitations of painting, and began to advocate the unifying characteristics of art and technology, so that the art of wall hangings was developed from the traditional folk production to the main development. The artwork created independently by the artist began a new chapter in fiber art.

Since the 20th century, the West has constantly emerged a variety of art schools. Art in all fields has been affected and impacted. Its main purpose is the rebellious tradition. During this period, it is also an important process for the art of wall art to go from traditional to modern. Known as the pioneer of modern wall hangings, famous French artist Jean Lulsa, in the 1930s he was determined to inject modern design concepts into the creation of fiber art, preserved the unique artistic language of wall hangings, and proposed in the creation must be combined with the surrounding environmental architecture. In the early 1960s, Jean Lüsselsa and many artists worked together to establish the "International Tradition and Modern Fibre Art Center" in Lausanne and founded the influential international fiber art exhibition.

From the late 1980s to the early 1990s, the art of fiber slowly returned to the walls. Most of the works appeared in the form of planes, which obviously had the characteristics of "post-modern". In the 21st century, the diversified features of fiber arts have become increasingly evident, and the types of materials have become more abundant. [3] For example, many modern technologies produce new materials that are used in a large number of applications. Wall hangings and the increasing number of space installations have jointly promoted the use of materials. The development of modern fiber arts is diversified.

Throughout history, it can be seen that the development pace of the entire history of fiber art is rapid. Fibrous wall painters have broken the limitations of traditional craftsmanship. Under the influence of contemporary art, they began to study and use comprehensive materials and techniques. Based on the application of traditional fiber materials, they began to explore the art language of other materials.

\section{Fiber Mural Language Features}

\subsection{The material language of fiber murals}

One of the characteristics of fiber fresco expression language is fiber material. Because of the unique physical properties of the material itself, the fabricated fiber fresco not only gives people a beautiful visual effect, but also makes people feel gentle and comfortable. Because of the different materials, this kind of beauty will bring different feelings to people. Even if it is the same material, its texture effect will be different. Materials used by modern fiber-art painters include traditional natural fibers, new natural fibers, and man-made fibers. Natural fibers include fibers commonly found in the natural world such as cotton, hemp, wool, and silk; novel natural fibers include mulberry silk, wheat straw, corn leaf, and apocynum; synthetic fibers include nylon, metal fibers, ceramic fibers, and others. It also uses "ready-made" materials. The physical properties of fiber materials can create different psychological responses. [4] For example, the feeling of silk gives a smooth and delicate feeling; the feeling of cotton and linen gives a feeling of being simple and 
rough, and different materials can make people feel different. At the same time, fiber materials are highly malleable. Fiber artists create a variety of texture effects through techniques such as weaving and winding, and different types, numbers, and colors of line overlays and covers also produce different texture effects.

Material is one of the most important factors for artist's creation. For artists, it is no longer a simple stacking of multiple materials, but it gives new expressions based on the essential attributes of the material. Miriam Shapiro tried to take a fresh look in his works to appreciate the beauty of the materials and techniques used by female artists throughout history. When she moved to California in the late 1960s, Shapiro entered the career as a hard-edged artist, and she became deeply fascinated by the metaphor of the undisguised femininity that she saw in her abstract paintings. Shapiro's involvement in the material used in a doll house created by the "House of the Woman" project inspired her and she began making giant stitching collages made of fibers collected from antique exhibitions and bazaars. Quilts, buttons, decorative sequins, lace trim and ruffled edges. She refers to these works as "the women's era." "The decomposition of a kimono" is one of a series of giant "feminine era" collages created based on Japanese kimono, fan and robe designs. This huge piece repeats the shape of a kimono with a large number of gorgeous fabric pieces.

Another artist, Annika, believes that although digital cameras can record images in digital cameras, computer digital technology cannot give full play to any color. Warm life picture. Weave each theme with light and texture, create detailed and vivid images, intertwined lines of different colors, and sometimes she also uses shiny golden lines as the focus to weave various stories in life. The center part of "The Queen's Wedding" focuses on the scene of the Queen's wedding. The surrounding frame is composed of small pieces cut out from multiple pictures. The work uses traditional weaving shapes and modern forms to express the content of the picture.

It can be seen that with the continuous development of social science and technology, fiber materials will be more and more abundant, and the material language will always be one of the important characteristics of fiber murals [4].

\subsection{Fiber mural process language}

In addition to the characteristics of the material itself, fiber murals are even more important in their unique process language. People make use of the plasticity of fiber materials, through different materials and weaving, embroidering techniques for processing and then create, creating a unique texture beauty. The basic methods often used in weaving include weaving, weft knitting, tufting, and tufting. Different weaving methods produce different visual effects, the same shape and the same material, and different weaving techniques. The visual effects will also be different [4].

For example, weaving is an old hand-made textile technique. It uses a fiber material such as wool or silk as a weft to interweave in the front and back spaces of the warp threads according to the needs of the screen. Each colored weft thread is woven back and forth through the warp threads in the pattern range. Express the figure in the image so far. [3] The warp threads that do not pass through the weft are formed by the crossing of the color and weft lines required for other graphics. The woven patterns are the same on both sides of the color, and the left and right directions are reversed. The weft-knitting method is the most basic weaving method for the expression of fiber art, and it is also the main creative method of contemporary fiber art. The weft-knitting method uses a variety of fiber materials for latitude and weaves on single warp, double warp, or multiple warp threads to form a rich and varied texture. Such as "Ribbon", "Patterns", "Tue Words", and even beads, etc., the combination of various weaving methods and flexible use can produce a rich variety of texture effects. The planting method is a process in which the warp and weft threads are interlaced into plain weaves, and the fibrils in the adjacent two warp threads are planted into knots. This technique uses the cross-section of the line to express the effect of the work. The thickness is completely determined by the warp and craftsmanship. Different thicknesses give people different visual perceptions. The work is composed of dense and orderly upright yarns, hence the name "Tufted". The tufting weaving method has the same principle as the tufting weaving method. The difference is that the surface of the tufted fabric is a dotted pile, and the surface of the tufted fabric 
is a curved pile loop. From this, it can be seen that the creation of fiber murals requires the artist to be able to master the production process skillfully. Only in this way can the pure fiber material become more colorful, and convey the unique visual language to the viewers, thereby generating visual and emotional resonance.

The works of Peterson's Dream fully illustrate this point. The artist Kiwi Candarelli encountered not only the paint oil in the creation, but the knitting and weaving yarns. He used Kobilin's weaving skills to perform the crafting for each part and use the weaving of the lines. The natural texture of the material and the color of the material itself fully express the creative thinking, and use thousands of color lines. The work of the characters of different classes and the creatures of the natural world was performed incisively and vividly. This work has aroused strong reaction in Europe. People can hardly believe that the artist has made it by hand. Since Kiwi Kandarelli's work is entirely based on Kobilin's weaving technique and uses a flat form, it is called "King of Gimping." Another artist, Joan Schultz, specializes in quilting techniques and won the Gold Award at the "World Quilting Exhibition" in Tokyo, Japan. She only began to study folk quilting techniques in the years since she had no family history and relevant experience. However, her unique feminine consciousness and poetic spirit led her to regard quilting as a medium for art rather than just a type of art that has been passed down until now. Quilting method is the use of spelling, make up, smashing, sewing process methods to combine various rag heads together to form a variety of patterns, and some also need to fill objects such as cotton, so that the work presents a three-dimensional effect. The original quilting was a purely handmade process. Due to the prevailing living conditions, in order to save the fabric, various kinds of rags were cut into the desired shapes and then stitched together to form different patterns. The folk baner was made in this way with a hundred clothes. Five venomous patterns will be sewn into the quilted product, and the pattern will be partitioned with a quilting process. The products are mainly quilted and quilted. Joan Schulz is an unconventional quilting and collage artist who is influenced by pop art and is good at using newspapers, letters, posters, and digital photos in his life. Graffiti, transfer, collage and stitching as well as printing and dyeing and other comprehensive means for creation. Her work uses materials that are familiar to us all through unconventional and unexpected ways [3].

In short, the fiber wall painter must understand and master all kinds of weaving techniques. He can skillfully mix and match these weaving textures according to the needs of the concept, and fully express the performance of the work. It can be seen that weaving technology language should be the main factor for fiber artists to achieve the final visual effect of their works and become a personal language that cannot be ignored in the creation of fiber murals.

\subsection{Spatial languages of fiber murals}

Modern people all live in the cold space environment such as steel bars, cement, concrete, etc. People are more and more indulging in nature, and fiber murals exactly satisfy people's emotional needs in this regard. Once the fiber fresco is on the wall, the material and texture of the murals are related to the space environment where the frescoes are placed, enabling the entire building to present a soft and easy-going environment. For the unsatisfactory areas of the building space itself, it can also be done through fiber murals. Adjustment and perfection. Fibre frescoes can create a different atmosphere in the space environment, which can be decorated magnificently by the wall frescoes on the walls and can be rendered soft and beautiful. For example, the artist's "Jinqu Qun" created by artist Janet Ai Ma Lin, the work breaks the traditional weaving technique and regular rectangular composition, and uses various dyed linen yarns and yarns to sew manual and machine stitches. The combination of system and weaving creates the overall effect of the bas-relief. The geometric elements and bright colors are used for the wall hanging. [3] The work was placed on the wall of the office, and the wall-mounted wave-like shape contrasted with the dull construction environment. At the same time, vivid colors and textures added an active atmosphere to the entire space.

At the same time, the fiber material has a good sense of touch, so that people get a sense of warmth and belonging, and play a role in the coordination of space and human relationships. For 
buildings, different functional building spaces will form different spatial forms. For example, hospitals, hotels and other spaces will give people different emotions. When designing a work, the wall painter should strengthen this feeling of space according to its spatial form. He must base himself on the experience and feelings of the space environment and achieve the fusion of the space environment and the fiber fresco to create a harmonious art atmosphere. Joyce Lopez is an international traveler and photographer. Her work is inspired by the momentary memories of architecture, people, animals, and nature taken while traveling the world. She uses colorful fiber material wrapped around a metal tube to express her feelings. [5] Therefore, "bright colors and structural designs with strong visual effects originate from the influence of multiculturalism," which is a distinctive feature of Joyce's fiber art work. Her works can express the beauty of the architectural structure and integrate with the interior space of the United States. "Dream" has a strong decorative effect. His color is in harmony with the whole environment. The active colors in the wall decoration will calm the environment with an already too calm environment and inject vitality into the building [5].

\section{Conclusion}

In summary, the exploration of the artistic language of fiber murals is to gain a deeper understanding and understanding of fiber materials, to better find materials, to use materials, and to use fiber materials as a better medium for mural painting. The artistic language of the fiber fresco provides a source of inspiration for the work, providing the basis for the completion of the work and constituting an indispensable element of the fiber fresco.

\section{References}

[1] Fiber Art, Lin Lecheng, Wang Kai, Shanghai Pictorial Publishing House, April 2006, 8-52.

[2] "Creative and performance of fiber art", Gong Jianpei, Southwest China Normal University Press, February 2006, 69-79.

[3] "Fiber Art Design and Production", Ren Guanghui, Hebei Art Publishing House, April 2009, $10-26$.

[4] "Fiber Art Design", Cai Congzhu, Hubei Fine Arts Publishing House, June 2006, 18-30.

[5] "Modern Fiber Art Design" by Zhu Jinhui, Shaanxi People's Fine Arts Publishing House, March 2003 Edition, 45-51. 